Gut, 1984, 25, 1384-1391

\title{
Relationships of human antroduodenal motility and transpyloric fluid movement: non-invasive observations with real-time ultrasound
}

\author{
P M KING, R D ADAM, A PRYDE, W N MCDICKEN, AND R C HEADING \\ From the Department of Therapeutics and Clinical Pharmacology, and Department of Medical Physics, \\ Royal Infirmary, Edinburgh
}

SUMmARY To study the relationships between gastric antral and proximal duodenal motor activity, and the movement of liquid across the pylorus, 10 healthy volunteers were given a test meal of dilute orange juice and bran, and events at the gastric outlet monitored by real-time ultrasound. A total of 116 complete gastric peristaltic cycles were observed and in $86 \%$ of these, associated proximal duodenal contractions were seen. Transpyloric fluid movement, as reflected by the movement of the bran particles, occurred as brief episodes during the time when the pylorus was open. Distal flow, in episodes lasting 2-4 seconds, was seen to occur in $81 \%$ of the 116 complete cycles and $75 \%$ of these episodes occurred just after the relaxation of the terminal antrum, pylorus, and proximal duodenum. The remainder occurred shortly before the terminal antral contraction. Retrograde flow, in episodes of up to 5 seconds, occurred in $78 \%$ of observed cycles with the majority occurring immediately before contraction of the terminal antrum. Our findings indicate that transpyloric fluid movement occurs in brief episodes lasting a few seconds only and that retrograde flow across the pylorus occurs in normal subjects. This pattern of fluid movement can bear no direct relationship to a steadily advancing antral peristaltic contraction, nor be wholly attributable to constant intragastric pressure.

Currently available methods for the study of gastric emptying in man do not provide information about the movements of gastric contents in relation to individual gastric peristaltic contractions. Manometric methods permit observation of the timing and magnitude of pressure changes within the gastric lumen ${ }^{1-4}$ and some electrical recordings from the human stomach and duodenum have been obtained $^{256}$ but although both of these give information about muscle contraction, they do not identify the movement of intragastric contents. Simultaneous studies of antral contractions and gastric emptying in man have been undertaken using intubation methods, ${ }^{57}$ and also with a scintigraphic procedure, ${ }^{89}$ but much of the current knowledge about the relationships between flow of luminal contents and contractions of the human stomach, pylorus, and duodenum has been obtained from radiological investigations using contrast media. ${ }^{3} 10$

Address for correspondence: P M King. Department of Therapeutics, and Clinical Pharmacology, Royal Infirmary, Edinburgh EH3 9YW.

Received for publication 21 February 1984
These are, however, far more difficult than they initially appear. ${ }^{37}$ Double contrast techniques may irritate the gastric mucosa ${ }^{11}$ and will cause gastric distension, inducing motility abnormalities, ${ }^{12}$ whereas with single contrast procedures, it is often impossible to determine direction of movements of the gastric contents in response to an antral contraction. ${ }^{13}{ }^{14}$ Furthermore, the duration of radiographic studies in man is limited by considerations of radiation dosage. ${ }^{12} 131516$

We have previously described the application of real time ultrasonic imaging to the study of gastric motility in $\operatorname{man}^{17}$ and now report our use of the technique to examine the relationships between peristaltic contractions and the movement of gastric contents through the pylorus.

\section{Methods}

SUBJECTS

Studies have been attempted on 17 healthy normal subjects. There were nine men and eight women 
with an age range of $21-62$ years. After fasting overnight, the subject was given a test meal of 500 $\mathrm{ml}$ water flavoured with orange juice and warmed to $37^{\circ} \mathrm{C}$, to which $0.5 \mathrm{~g}$ of chopped and sieved bran was added. The test meal had an osmolarity of 285 $\mathrm{mOsm} / \mathrm{l}$ and a $\mathrm{pH}$ of $2 \cdot 8$; the wet particle size of the bran was $1.5 \mathrm{~mm}$. Ultrasound scanning of the upper abdomen was then performed using a rotating transducer real-time ultrasound scanner with a 5 $\mathrm{mHz}$ probe (Fischer Ultrasound Limited). Scanning was carried out for a period of up to 30 minutes after consumption of the test meal and recorded on video tape. Because previous experience had shown that satisfactory scans were not obtained from recumbent or supine patients, the present investigation was undertaken with the subject seated upright.

The immediate objective was to obtain and maintain an image of the distal antrum, pylorus, and proximal duodenum. The optimum position for the scanner head on each subject's abdomen was found by initially placing the scanner on the abdomen in the midline at the level of the transpyloric plane and subsequently moving it to the right. The probe was initially held to scan horizontally to identify the antrum and then rotated to an angle of up to $60^{\circ}$ to bring the distal antrum, pylorus, and proximal duodenum into line. Small deviations from the above position were necessary according to variation in the subject's anatomy, and normal respiratory movements required that the probe was hand-held so that fine adjustments could constantly be made to compensate for them.

The video recordings were then reviewed to identify the periods when a clear image of the distal antrum, pyloric channel and proximal duodenum was maintained, and there was a sufficient concentration of bran particles suspended in the luminal contents to identify movement through the pylorus, throughout a period of several consecutive antral contractions which lasted a minimum of 2 minutes and up to 4 minutes. Figure 1 shows two photographs from a satisfactory record to illustrate the criteria. The lumen of the stomach and proximal duodenum contains a density of bran particles sufficient to establish their direction of movement through the pylorus and the pyloric channel is visualised. In Figure 1a a peristaltic wave is appearing in the mid antrum whereas 10 seconds later, the wave is approaching the pylorus (Figure 1b).

A satisfactory recording was arbitrarily defined as one in which these criteria were met and sustained for at least 2.5 minutes. The segments to be analysed were often more readily and quickly selected by viewing a fast replay of the recording, allowing rapid exclusion of unsatisfactory data. The timescale compression also markedly enhanced subjective appreciation of regular patterns of events. These sections of the record were then analysed at normal speed with the aid of a simple event marking system on a 4-channel chart recorder. The terminal antrum contractions (contractions of the immediate prepyloric area) and proximal duodenum contractions were both timed from the point where the opposing gastric or duodenal walls began to occlude their lumena until they subsequently relaxed and the lumena became widely patent. A first observer noted this, while a second observer recorded the direction of particle movement through the pylorus. Forward flow was defined as movement of particles through the pylorus from the stomach to the proximal duodenum, and retrograde flow as movement through the pylorus from the proximal duodenum to the stomach. The observations on the direction of particle movement do not reflect their rate of movement and so do not differentiate slow drift from rapid flow. The video tapes were reviewed on several occasions, so that each variable was studied by two observers and at least on six occasions in all. The individual observations on each event were then averaged to provide a 'best estimate' of the timing and duration of each variable studied. The data were subsequently transferred to a specially designed programme on an Apple II computer to allow data storage, subsequent retrieval, and statistical analysis.

An example of repeated analysis of the video record with the event marking system is illustrated in Figure 2. An event was judged to have occurred if two or more closely grouped observations by two observers were marked on the trace. Overall, this criterion resulted in rejection of $15 \%$ of the individual observations. Some observer variation is apparent in Figure 2, particularly in respect of retrograde flow.

\section{Results}

Satisfactory recordings were obtained in 10 of the 17 subjects. Three of these subjects had satisfactory recordings carried out on two separate occasions and a further subject had three separate recordings. These 15 recordings form the basis of this study; each satisfactory period of recording lasted a minimum of 2.5 minutes and a maximum of 4 minutes. On some occasions it would have been possible to continue the analysis for up to 10 minutes but in the context of the present study a 4 minute limit seemed sufficient. In the remaining seven subjects, one or more of the previously mentioned criteria of a satisfactory recording could not be fulfilled. A similar set of observations was obtained 

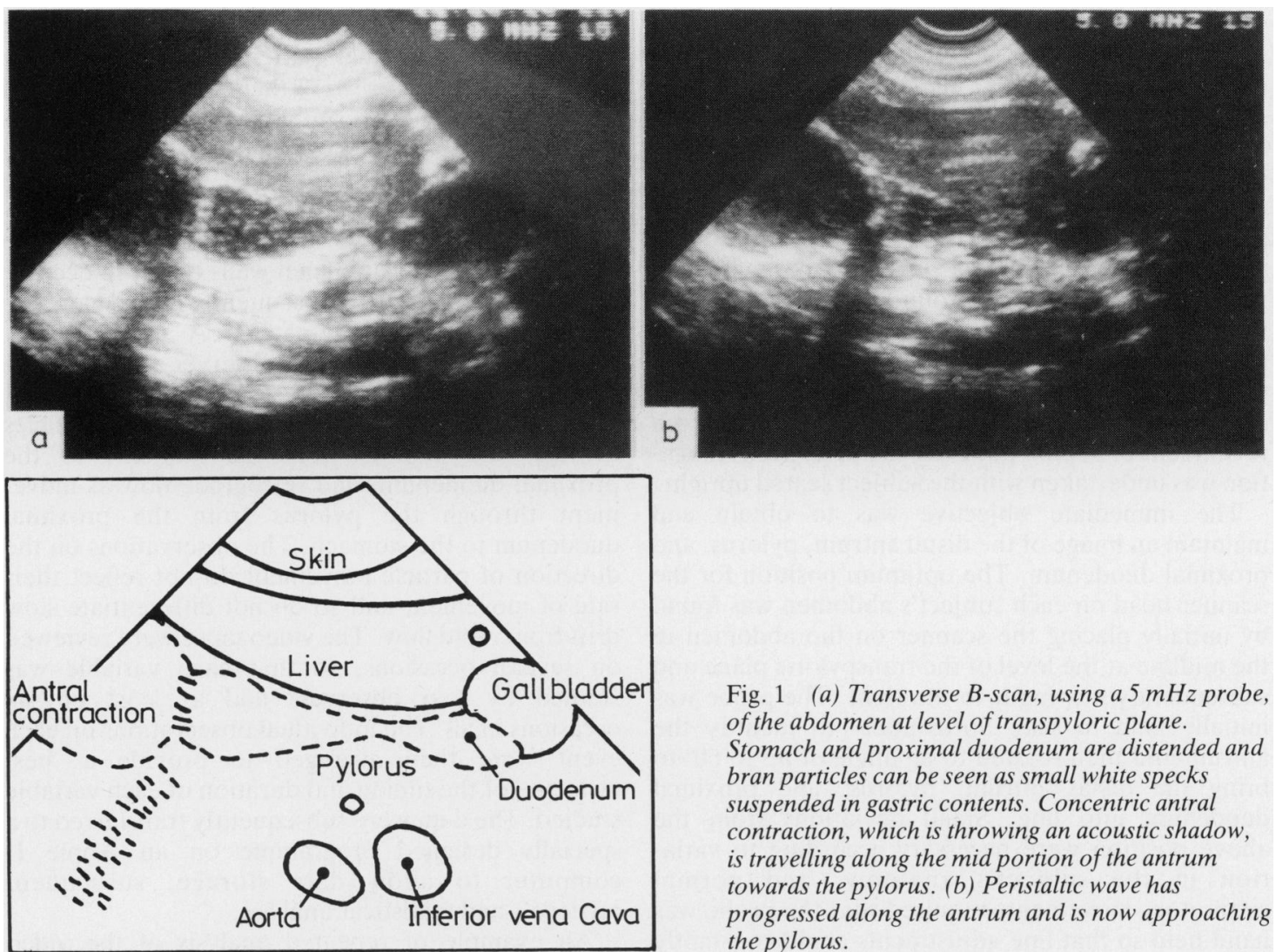

Fig. 1 (a) Transverse $B$-scan, using a $5 \mathrm{mHz}$ probe, of the abdomen at level of transpyloric plane.

Stomach and proximal duodenum are distended and bran particles can be seen as small white specks suspended in gastric contents. Concentric antral contraction, which is throwing an acoustic shadow, is travelling along the mid portion of the antrum towards the pylorus. (b) Peristaltic wave has progressed along the antrum and is now approaching the pylorus.

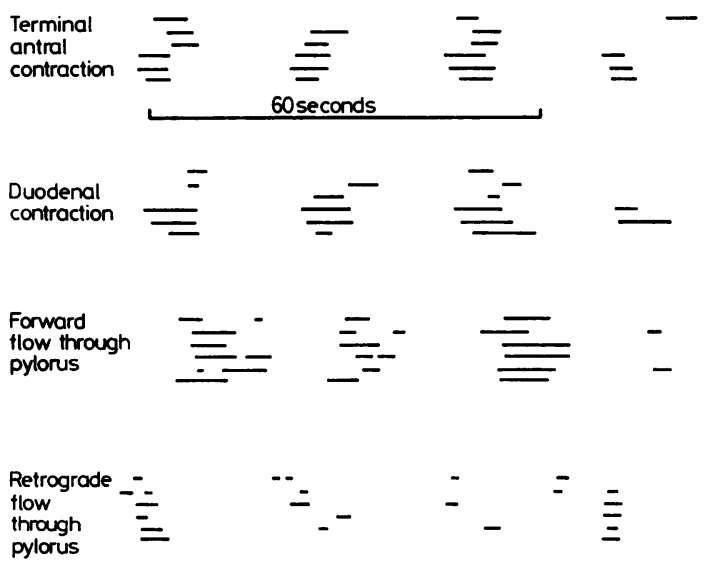

Fig. 2 4-channel chart recording of repeated analysis of the timed events from subject 3 . Individual observations, represented by single line, on each event are subsequently compared and averaged to provide 'best estimate' of timing and duration of terminal antral and duodenal contraction and particle movement through pylorus. 
Fig. 3 Comparison of timed events in four separate subjects. 'Best estimates' of timing and duration of terminal antral contractions $(T A C)$, proximal duodenal contraction (DC), and episodes of forward flow $(F F)$ and retrograde flow (RF) through the pylorus from four different subjects have been plotted to illustrate pattern of events and to allow comparisons to be made.

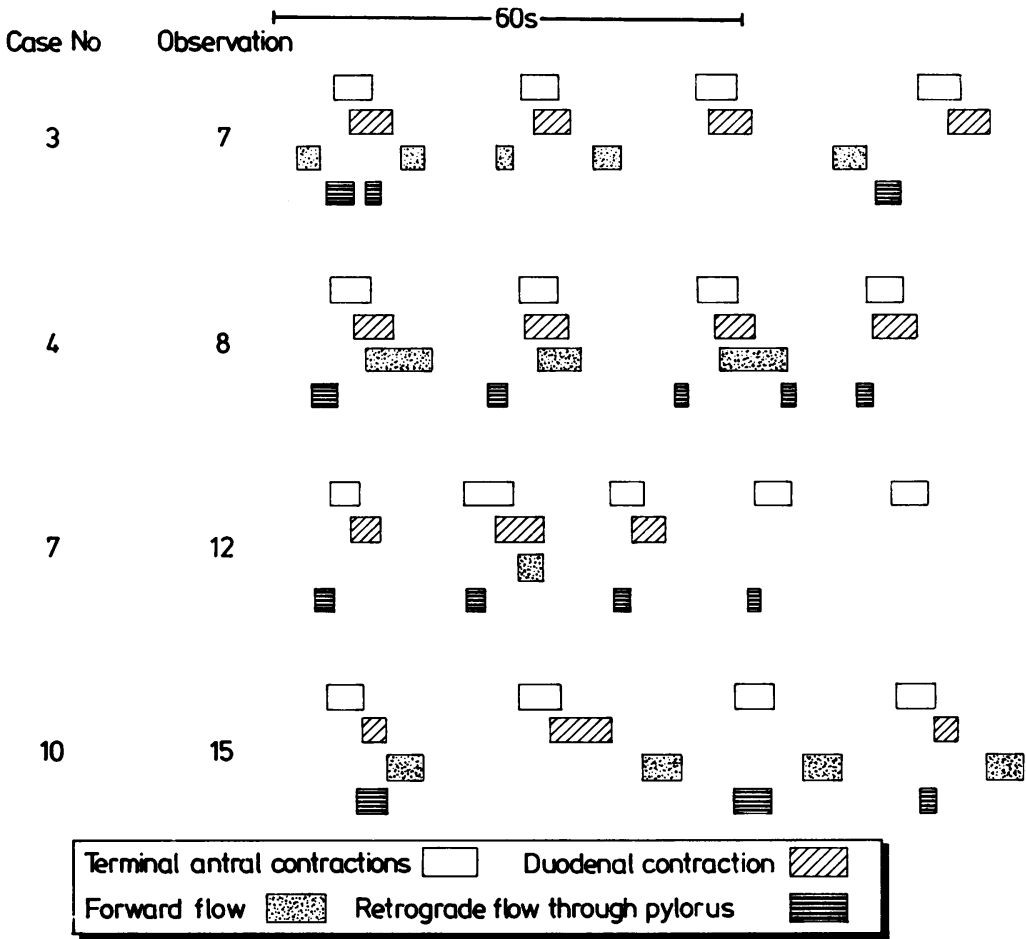

this sequence of cycles from subject 7 despite an opening and closing pylorus and steadily advancing antral contractions. Although the duration of forward flow in subject 4 is shorter than subject 3 , it could be seen from the video tapes that the rate of particle movement in the former was considerably greater then the latter. The volume of fluid passing through the pylorus cannot be inferred from the duration of the period of flow. Retrograde flow is seen in most cycles.

The 15 sets of satisfactory recordings contained a total of 116 complete peristaltic cycles; the number of events observed and their mean duration are shown in Table 1 . The mean gastric peristaltic cycle time observed in each subject is shown in column 4 of Table 1 and the range is from 18.7 to 29.6 seconds. Detailed analysis of the cycle times from each of the 15 sets of satisfactory observations has shown a significant difference in the mean times between sets of data when compared with the intervals within each set $(F=7 \cdot 38: p<0 \cdot 01)$. The standard deviation between the mean cycle times of the 15 sets of observations was considerably greater than within each individual set (9.25 compared with 3.41). More interestingly, however, there was no significant difference in cycle times between the sets of data from the individuals who have been satisfactorily recorded on different occasions (Table 2). Each subject, using this particular test meal, would appear to have cycle times which remain relatively constant but may differ from the next individual.

The duration of the terminal antral contraction was about 4 seconds (mean 3.93 seconds SD \pm 0.8 ) with little individual variation. Pyloric closure invariably occurred as the gastric peristaltic wave reached the pylorus at the midpoint of the terminal antral contraction. Contractions of the first part of the duodenum were associated with $86 \%$ of the terminal antral contractions. Ninety two per cent of these duodenal contractions occurred immediately after the terminal antral contraction, $5.5 \%$ simultaneously and only $2.5 \%$ (3) were ectopic. There was some variation in the duration of the contraction of the first part of the duodenum which lasted about 5 seconds (mean 4.93 seconds SD \pm 1.75 ).

Transpyloric fluid movement, as reflected by the movement of the bran particles, occurred as brief episodes during the time when the pylorus was open. Forward flow was seen to occur in $81 \%$ of the 116 complete cycles and lasted about 2-4 seconds (overall mean 3.0 seconds SD $\pm 1 \cdot 2$ ). Seventy five per cent of these episodes occurred after relaxation 
Table 2 Comparison of individual mean gastric peristaltic cycle times

\begin{tabular}{|c|c|c|c|c|}
\hline Subject & Observation & $\begin{array}{l}\text { Mean cycle } \\
\text { time }\end{array}$ & $t^{*}$ & $p$ \\
\hline 1 & $\begin{array}{l}1 \\
2\end{array}$ & $\begin{array}{l}29 \cdot 6 \\
29 \cdot 4\end{array}$ & $0 \cdot 115$ & $0 \cdot 1<p<0.5$ \\
\hline 2 & $\begin{array}{l}3 \\
4\end{array}$ & $\begin{array}{l}26 \cdot 8 \\
24 \cdot 0\end{array}$ & 1.72 & $0 \cdot 1<p<0.2$ \\
\hline 2 & $\begin{array}{l}4 \\
5\end{array}$ & $\begin{array}{l}24 \cdot 0 \\
24 \cdot 4\end{array}$ & $0 \cdot 16$ & $0 \cdot 1<p<0.9$ \\
\hline 3 & $\begin{array}{l}6 \\
7\end{array}$ & $\begin{array}{l}24 \cdot 5 \\
22 \cdot 8\end{array}$ & $0 \cdot 87$ & $0.4<p<0.5$ \\
\hline 4 & $\begin{array}{l}8 \\
9\end{array}$ & $\begin{array}{l}24 \cdot 6 \\
25 \cdot 2\end{array}$ & $0 \cdot 37$ & $0.7<p<0.8$ \\
\hline
\end{tabular}

* Unpaired $t$ test.

of the terminal antrum, pylorus and duodenum with the remaining $25 \%$ occurring just before the terminal antral contraction. Retrograde flow, in episodes lasting up to about 5 seconds (mean 2.5 seconds SD \pm 2 ), occurred in $78 \%$ of observed gastric cycles. Sixty one per cent of these episodes occurred just before the terminal antral contraction with $39 \%$ following it. Although the impression given by a large number of observations is that many of the episodes of retrograde flow occurred just after a distinct episode of forward flow, there was no consistent or measurable pattern between or within individuals.

It is clear that the direction of particle movement and its duration do not reflect the flow rate through the pylorus. An impression of the flow rate, however, could be gained from the number of particles which were seen to flow through the pylorus and the rate at which they moved. There appeared to be much variation in the rate of both forward and retrograde movement of particles.

The same general pattern of distal stomach and duodenal contraction and luminal movement was also observed in the partial recordings made from the seven other subjects from whom satisfactory recordings could not be obtained. No observations made on these subjects were inconsistent with the findings from the 15 satisfactory recordings.

\section{Discussion}

This investigation has shown that real-time ultrasonic imaging can be applied to observation of motor activity at the human gastric outlet. The observations made are most readily compared with previous radiograph fluoroscopic studies in man and experimental animals, with the advantage that more information is gained about the passage of gastric contents through the pylorus. Studies based on gastric or duodenal intubation methods in man, or using strain gauges and duodenal cannulae in animals will identify motor activity and measure overall rates of gastric emptying and duodenogastric reflux, but these methods do not have the temporal resolution to distinguish flow through the pylorus at one moment from the flow a few seconds later. ${ }^{12} 18$ Quite obviously, radiographic studies do allow excellent temporal resolution of events at the gastric outlet, and are able to identify when a contraction occurs, but there can be diffculties in determining the direction of movement of antral and duodenal contents. ${ }^{1314}$

We presume our findings with the ultrasonic technique relate to the behaviour of liquids as they empty from the stomach. Although the bran particles producing the ultrasound echos were strictly solids suspended in the liquid gastric contents, the particles were so small that their behaviour may reasonably be taken to represent movements of the liquid phase of the gastric contents, rather than the behaviour of intragastric solids. Currently available evidence suggests that food particles less than $2 \mathrm{~mm}$ in diameter empty from the human stomach indistinguishably from liquids. ${ }^{12}$ Bran with a wet particle size of $1.5 \mathrm{~mm}$ was chosen as an ultrasonically identifiable marker of fluid movement because it was simple to prepare and did not aggregate.

The most unexpected observation made during the present investigation was the timing and episodic pattern of movement of gastric contents through the pylorus. Our findings indicate that emptying of the gastric contents through the pylorus occurs in discrete episodes of 2-5 seconds only, and that the majority of these occur as the terminal antrum, pylorus and duodenum relax at the end/start of each gastric peristaltic cycle. This brief period of forward flow often terminated abruptly and was sometimes immediately followed by a period of retrograde flow. This pattern appears to be in conflict with the traditional view that gastric emptying of liquids occurs either as gushes in response to the pumping action of the antral peristaltic contractions, $91920-22$ or as a steady flow, induced by a pressure gradient maintained and regulated by the tone of the proximal stomach ${ }^{722-26}$ and interrupted only by the intermittent closure of the pylorus. ${ }^{23}$ Clearly the intermittent pattern of transpyloric flow we have observed can bear no direct relationship to a steadily advancing antral peristaltic contraction, nor can it be attributed to constant intragastric pressure.

Because fluid movement can occur only as a response to a pressure gradient across the pylorus, ${ }^{11} 1826$ It would seem that rapid fluctuations in this pressure gradient must occur. Whether there 
are rapid changes in contractile tone of the proximal stomach, or rapid fluctuations in intraduodenal pressure remains to be determined. These findings, however, clearly invite further consideration of the idea that the discharge of fluid from the stomach is regulated as much by a process of 'duodenal receiving' as by 'gastric emptying'.

In $78 \%$ of all gastric cycles, episodes of retrograde flow through the pylorus were observed. Sixty one per cent of these episodes occurred while the antral wave was approaching the pylorus and still remained non-occlusive, but then these episodes ended abruptly as the channel was obliterated by the terminal antral contraction. The remaining 39\% occurred after relaxation of the terminal antrum and pylorus when their lumena were once again patent. Most episodes of retrograde flow through the pylorus were not associated with demonstrable contraction of the proximal duodenum and the impression given by the video image was that duodenal contents from the second part passed through the relaxed first part of the duodenum and pylorus into the stomach. Occasional contractions of the second part of the duodenum were observed to occur in mid cycle when the pylorus was still open and these were associated with retrograde flow into the stomach. None of the observed episodes of retrograde flow, however, were associated with recognisable true retroperistaltic waves originating in the second part of the duodenum, which have been described in humans in the presence of peptic ulceration. ${ }^{27}$ In addition, on several occasions when the second part of the duodenum was well visualised, contraction of this part were seen to occur when the pylorus was closed and retrograde flow into the stomach did not then occur. While this is consistent with other evidence which suggests that duodenogastric reflux occurs in healthy individuals, ${ }^{16} 28-31$ it should be noted that many of the observed episodes of retrograde flow through the pylorus followed immediately after an episode of flow from the stomach to duodenum. It is therefore possible that the refluxed fluid had not become mixed with intraduodenal bile or pancreatic secretions and thus it did not necessarily represent duodenogastric reflux in the usual sense of the term, which carries an implication that duodenal fluid containing bile has entered the stomach. Nevertheless, the present observations have shown clearly that a period of retrograde flow at the pylorus occurs during most gastric peristaltic cycles in normal man.

The range of mean gastric peristaltic cycle times from 18.8 to 29.6 seconds is entirely consistent with the reported frequency of gastric slow wave activity at 2.1 to 3.7 cycles per minute. ${ }^{20}$ In addition, the consistently similar mean cycle times of individuals confirms the statement that individuals are consistent to within $10 \% .{ }^{20}$ Ninety seven per cent of observed contractions of the proximal duodenum (bulb) occurred immediately after or simultaneously with the terminal antral contraction. Although the frequency of the duodenal pacemaker is around $\mathbf{1 1}$ cycles/minute it is recognised that the motility of the bulb differs from the rest of the duodenum ${ }^{3}$ and that the terminal antrum, pylorus, and proximal duodenum function as the gastroduodenal unit. ${ }^{32}$ Migration of antral slow wave activity across the pylorus is thought to modify the response of the muscle of the proximal duodenum to the firing of the duodenal pacemake ${ }^{22}$ and produces a progressive wave of contraction in antrum, pylorus and proximal duodenum.

Intragastric volume, particle size, $\mathrm{pH}$, calorie content and osmolarity are all factors which are thought to influence gastric emptying. We arbitrarily chose a test meal of orange juice and bran because we had previously shown that $500 \mathrm{ml}$ of liquid was sufficient to distend the stomach producing the fluid solid interface required for ultrasonic imaging and also this volume would allow around 30 minutes of possible observation time before the stomach emptied. The addition of orange juice to the water and bran mixture gave the meal an osmolarity of 285 $\mathrm{mOsm} / \mathrm{l}$ and a $\mathrm{pH}$ of $2 \cdot 8$. Thus although we cannot be entirely certain about the effect of the various components of our test meal on gastroduodenal motor activity and emptying we have established a definable baseline for future comparisons.

There are obvious attractions in a non-invasive technique which allows prolonged study of events at the gastric outlet. ${ }^{19} 33$ We must emphasise, however, that in our experience the use of real-time ultrasonic imaging for this purpose is not easy and so far has been successful only for relatively brief periods in about half of the subjects studied. The two main problems are firstly, individual anatomical variation which sometimes renders it impossible to display the proximal duodenum, pyloric channel, and distal antrum in a single plane, and secondly, the clarity of imaging is much impaired by subcutaneous fat. No useful recording has been obtained from an overweight individual using the 5 $\mathrm{mHz}$ probe. Despite these difficulties the present study has shown ultrasonic imaging can be used to study events at the gastric outlet and at present there is no other technique which can generate the same information. The intermittent and episodic pattern of movement of gastric contents through the pylorus clearly requires further study given that the present observations were made with a single test meal which was isotonic, of low nutrient value, and of low 
pH. Nevertheless it would seem that influences which modify the intermittent pattern of emptying seen with this meal must be fudamental to the physiology of gastric emptying.

This study was supported by a grant from the Scottish Home and Health Department. The authors wish to thank Mrs J Brown for technical assistance and Mrs S Anderson who typed the manuscript.

\section{References}

1 Fisher R, Cohen S. Physiological characteristics of the human pyloric sphincter. Gastroenterology 1973; 64: 67-75.

2 Anderson S, Grossman MI. Profile of $\mathrm{pH}$, pressure, and potential difference at gastroduodenal junction in man. Gastroenterology 1965; 49: 364-71.

3 Friedman G, Wolf BS, Waye JD, Janowitz HD. Correlation of cineradiographic and intraluminal pressure changes in the human duodenum and analysis of the functional significance of monophasic waves. Gastroenterology 1965; 49: 37-49.

4 Valenzuela JE, Defilippi C. Pyloric-sphincter studies in peptic-ulcer patients. Am J Dig Dis 1976; 21: 229-32.

5 Kaye MD, Mehta SJ, Showalter JP. Manometric studies of the human pylorus. Gastroenterology 1976; 70: 477-80.

6 Stoddard CJ, Smallwood R, Brown BH, Duthie HL. The immediate and delayed effects of different types of vagotomy on human gastric myoelectrical activity. Gut 1975; 16: 165-70.

7 Rees WDW, Go VLW, Malagelada JR. Simultaneous measurement of antroduodenal motility, gastric emptying, and duodenogastric reflux in man. Gut 1979; 20: 963-70.

8 Stacher G, Bergman H, Havlic E, Schmierer G, Schneider S. Effects of oral cyclotropium bromide, scopolamine n-butyl-bromide, and placebo on gastric emptying and antral motor activity in healthy man. [Abstract]. Gut 1983; 24: A359.

9 Jacobs F, Akkermans LMA, Oei Hong Yoe, Hoekstra $A$, Wittebol $P$. A radioisotope method to quantify the function of fundus, antrum, and their contractile activity in gastric emptying of a semi-solid meal. In: Weinbeck M, ed. Motility of the digestive tract. New York: Raven Press, 1980: 233-40.

10 Smith AWM, Code CF, Schlegel JF. Sumultaneous cineradiographic and kymographic studies of human gastric antral motility. J Appl Physiol 1957; 11: 12-16.

11 Rock E, Malmud L, Fisher RS. Motor disorders of the stomach. Med Clin North AM 1981; 65: 1269-89. •

12 Dubois A. Pathophysiology of gastric emptying: methods of measurement and clinical significance. $J$ Clin Gastroenterol 1979; 1: 259-66.

13 Fisher RS, Malmud LS, Bandini P, Rock E. Gastric emptying of a physiologic mixed solid-liquid meal. Clin Nucl Med 1982; 7: 215-21.

14 Griffith GH, Owen GM, Campbell PH, Shields R. Gastric emptying in health and gastroduodenal disease. Gastroenterology 1968; 54: 1-7.

15 Sheiner HJ. Gastric emptying tests in man. Gut 1975; 16: 235-47.

16 Mullèr-Lissner SA, Fimmel CJ, Sonnenberg A, et al. Novel approach to quantify duodenogastric reflux in healthy volunteers and in patients with type I gastric ulcer. Gut 1983; 24: 510-18.

17 Holt S, McDicken WN, Anderson T, Stewart IC, Heading RC. Dynamic imaging of the stomach by real-time ultrasound - a method for the study of gastric motility. Gut 1980; 21 : 597-601.

18 Weems WA. Intestinal wall motion, propulsion, and fluid movement: trends toward a unified theory. Am J Physiol 1982; 243: G177-88.

19 Brener W, Hendrix TR, McHugh PR. Regulation of the gastric emptying of glucose. Gastroenterology 1983; 85: 76-82.

20 Davenport HW. Physiology of the digestive tract. 4th ed. Year Book Medical Publishers Incorporated: Chicago, 1977: 41-57.

21 Cooke AR. Control of gastric emptying and motility. Gastroenterology 1975; 68: 804-16.

22 Bortoff A, Davis RS. Myogenic transmission of antral slow waves across the gastroduodenal junction in situ. Am J Physiol 1968; 215: 880-97.

23 Kelly KA. Gastric emptying of liquids and solids: roles of proximal and distal stomach. Am J Physiol 1980; 239: G133-5.

24 Heading RC. Gastric emptying: a clinical perspective. Clin Sci 1982; 63: 231-35.

25 Malagelada JR. Physiologic basis and clinical significance of gastric emptying disorders. Dig $\mathrm{Dis} \mathrm{Sci}$ 1979; 24: 657-61.

26 Strunz UT, Grossman MI. Effect of intragastric pressure on gastric emptying and secretion. Am J Physiol 1978; 235: E552-5.

27 Johnson AG. Peptic ulcer and the pylorus. Lancet 1979; 1: 710-2.

28 Keane FB, Dimagno EP, Malagelada JR. Duodenogastric reflux in humans: its relationship to fasting antroduodenal motility and gastric, pancreatic, and biliary secretion. Gastroenterology 1981; 81: 726-31.

29 Sonnenberg A, Muller-Lissner SA, Weiser HF,MullerDuysing W, Heinzel F, Blum Al. Effect of liquid meals on duodenogastric reflux in humans. Am J Physiol 1982; 243: G42-7.

30 Thompson DG. Duodenogastric reflux: is there any progress. Br Med J 1982; 284: 845-6.

31 Heading RC. Duodenogastric reflux. Gut 1983; 24: 510-8.

32 White CM, Poxon V, Alexander-Williams J. Effects of nutrient liquids on human gastroduodenal motor activity. Gut 1983; 24: 1109-16.

33 Bateman DN, Leeman S, Metreweli C, Wilson K. A non-invasive technique for gastric motility measurement. Br J Radiol 1977; 50: 526-7. 